\title{
Protracted growth impedes the detection of sexual dimorphism in non-avian dinosaurs
}

\author{
by DAVID W. E. HONE ${ }^{1 *}$ and JORDAN C. MALLON ${ }^{2 *}$ \\ ${ }^{1}$ School of Biological and Chemical Sciences, Queen Mary University of London, Mile End Road, \\ London, E1 4NS, UK; e-mail: d.hone@qmul.ac.uk \\ ${ }^{2}$ Palaeobiology, Canadian Museum of Nature, PO Box 3443, Station D, Ottawa, Ontario, K1P 6P4 \\ Canada; e-mail: jmallon@mus-nature.ca \\ *These authors contributed to the work equally
}

\begin{abstract}
Evidence for sexual dimorphism is extremely limited in the non-avian dinosaurs despite their high diversity and disparity, and despite the fact that dimorphism is very common in vertebrate lineages of all kinds. Using body size data from both Alligator mississippiensis and Rhea americana, which phylogenetically bracket the dinosaurs, we demonstrate that even when there is strong dimorphism in a species, random sampling of populations of individuals characterized by sustained periods of growth (as in the alligator and most dinosaurs) can result in the loss of this signal. Dimorphism may be common in fossil taxa but very hard to detect without ontogenetic age control and large sample sizes, both of which are hampered by the limitations of the fossil record. Signal detection may be further hindered by Type III survivorship, whereby increased mortality among the young favours the likelihood that they will be sampled (unless predation or taphonomic bias acts against this). This hindrance is counteracted by taphonomic bias against small body size. These, and other considerations relating to behavior and ecology, provide powerful reasons to suggest that sexual dimorphism in dinosaurs may be very difficult to detect in almost all currently available samples. Similar issues are likely also applicable to many fossil reptiles, or animals more generally.
\end{abstract}

Keywords: sexual dimorphism, sexual selection, dinosaurs, growth, ontogeny

\section{INTRODUCTION}

The clades that form the extant phylogenetic bracket for non-avian dinosaurs (birds and crocodylians) are both known to have multiple sexually dimorphic species, and indeed sexual dimorphism is common in numerous vertebrate lineages (Cunningham 1900, Shine 1989, Fairbairn et al. 2007, Fig 1). Sexual dimorphism has likewise been posited in non-avian dinosaurs (hereafter simply 'dinosaurs') on numerous occasions (summarized in: Chapman et al. 1997, Molnar 2005, Isles 2009, Mallon in press), but these studies have been shown to be problematic, owing to issues of sample size, experimental control, and methodology (Mallon in press), and 
have often failed later testing (e.g., Maiorino et al. 2015, Mallon in press). The apparent absence of sexual dimorphism in dinosaurs is therefore perplexing.

One possible explanation for its absence is mutual sexual section - the phenomenon where both sexes are ornamented, with males advertising for females and females advertising for males. This phenomenon is common in birds and has been suggested to be present in some dinosaurs (Hone et al. 2012), which may partly explain the apparent absence of dimorphism in the latter, especially with respect to large extravagant structures. However, even under mutual sexual selection, males and females may be dimorphic in their ornamentation (both sexes may bear ornaments but to different degrees), and the prevalence of dimorphism in other vertebrate lineages suggests some or many dinosaurs would likely show dimorphism in their ornaments or other traits, especially body size (sexual size dimorphism, or SSD).

The apparent absence of sexual dimorphism in dinosaurs has been highly contentious as a subject with major disagreements at to the possible degree of dimorphism, or even its very existence, and the potential functions of exaggerated structures that may be linked to sexual selection or other factors (e.g. see opposing views of Padian and Horner 2011a, b, 2014 and Hone et al. 2012, Hone and Naish 2013, Knell et al. 2013, Borkovic and Russell 2014). The concept of sexual dimorphism and sexual selection in dinosaurs specifically, and the fossil record generally, therefore remains problematic and warrants further investigation.

One aspect of studying sexual dimorphism in the fossil record that has received little attention is the influence of differential growth rates on signal detection. Nearly all birds and most mammals mature rapidly and reach somatic maturity at a similar time to sexual maturity (Stamps, 1993), and thus simultaneously reach near full adult ornament size as the majority of growth ceases. This condition is in contrast to many other vertebrate lineages, including dinosaurs, which typically spent a majority of their lives below asymptotic size (Horner et al. 2000, Erickson et al. 2004, 2007, Fig. 2). As a result, strong dimorphism may be easy to identify between groups of individuals of the same cohort, but across a wide range of ages and ontogenetic statuses, dimorphism may easily be cryptic among dinosaurs with extended periods of growth. In practice, it may be difficult to separate a young example of a larger morph from an older example of a smaller morph, especially when the ages of the individuals are unknown. Even large sample sizes, if randomly taken from across a wide range of individual sizes and / or ages, might not show any clearly dimorphic pattern.

Structures that are under sexual selection (and therefore may produce dimorphism) are likely to show rapid allometric growth as animals reach sexual maturity (Knell et al. 2013) and this has been demonstrated for some dinosaur species (Dodson 1975, 1976, Evans 2010, Hone et al. 2016a). However, ongoing increases in size of a structure, or a change in morphology (such as body size), over many years may add to the problem of a (non-binary) continuum of features in dinosaurs. Furthermore, in dinosaurs multiple indicators of 'maturity' - including the development of socio-sexual signaling structures, sexual maturity, somatic maturity (e.g. see Hone et al. 2016b) - may develop at different times and different rates even within single populations or closely related species (Erickson et al. 2007, Lee and Werning 2008). 
Given these considerations, we hypothesize that dimorphism may be common in dinosaurs but cannot be detected simply as a result of not controlling for age across the protracted growth trajectory. This is tested below using datasets for extant taxa drawn from the literature. We further test for the influence of survivorship strategy and taphonomic size bias on signal recovery.

\section{MATERIAL AND METHODS}

We examined sexual dimorphism in dinosaurs from the perspective of the extant phylogenetic bracket (Bryant and Russell 1992, Witmer 1995), which includes crocodylians and birds. Both clades exhibit sexual dimorphism to varying degrees (Fitch 1981, Cox et al. 2007, Székely et al. 2007). We selected the American alligator (Alligator mississippiensis) and the Greater rhea (Rhea americana albescens) because both are known from well-described growth data. More particularly sexual size dimorphism is strongly expressed in each (alligator males are 136\% larger than females [Wilkinson and Rhodes 1997]; rhea males are 128\% larger than females [Navarro et al. 2005]), providing a best-case scenario for mimicking dimorphic signal detection in the fossil record. We used the growth models of Wilkinson and Rhodes (1997) for the alligator, which employ a von Bertalanffy equation to describe total body length as a function of time. The models were developed for a population (77 males, 63 females) of wild-caught alligators from South Carolina, USA. We also used the growth models of Navarro et al. (2005) for the rhea, which employ a Gompertz equation to describe body mass as a function of time. The models were developed for farmed rheas ( 4 males, 6 females) from central Argentina, but ratite life history does not appear to vary greatly between wild and farmed populations (Cooper, 2005). Dinosaur growth is often compared to that of the ostrich (Struthio camelus) (e.g., Castanet et al. 2000, Erickson et al. 2007, Lee and Werning 2008), which we did not consider here because the most comprehensive studies did not recover a significant sexual size dimorphism (du Preez et al. 1992, Cilliers et al. 1995), although ostrich plumage is sexually dimorphic.

We replicated growth curves for males and females of each species using $\mathrm{R}$ version 3.2.3 (R Core Team, 2015). Growth was projected over the average lifespan of each species, which is ca. 50 years for the American alligator (Wilkinson and Rhodes 1997) and ca. 10.5 years for the Greater Rhea (BirdLife International 2017). We then simulated 1,000 normally distributed points about each curve for subsampling. The standard deviation of the residuals was permitted to increase logarithmically with age, following the parameters of the original studies (see supplementary data file 1, Hone and Mallon, 2017). Sexes of each species were randomly sampled (without replacement) at $\mathrm{n}=100, \mathrm{n}=75, \mathrm{n}=50, \mathrm{n}=25, \mathrm{n}=20, \mathrm{n}=15, \mathrm{n}=10$, and $\mathrm{n}=5$ to test for the effect of sample size on signal recovery, and a t-test was employed at each stage to test for sexual dimorphism in each species. Random subsampling and testing at each stage were repeated 1,000 times to determine how the different growth strategies of the alligator and rhea affect the likelihood of recovering a sexually dimorphic signal.

Given different survivorship strategies, population structure is typically such that 
individuals from all ages are not evenly represented. Alligators are Type III strategists (Erickson et al. 2006), and juveniles are often more abundant than adults in single populations. To test the effect of population structure on recovering dimorphism, we used data from Nichols et al. (1976:table 6) for an alligator population from the Rockefeller Wildlife Refuge in Louisiana, USA. These data were given as a distribution of total body lengths, which we converted to age estimates using the von Bertalanffy growth function described above. Percent composition was plotted against age, and a Gaussian function was found to best fit the data (Akaike Information Criterion $=10.507$ ) in PAST v. 3.11 (Hammer et al. 2001). This function was then used to estimate percent composition at regular integers from ages 0 to 50. This new age distribution was then used for subsampling as described above.

We also mimicked taphonomic size bias to test its effect on dimorphism signal recovery. Brown et al. (2013) showed that, within the fluvially-derived upper Campanian Dinosaur Park Formation of Alberta, Canada, there is a strong bias against individuals $<60 \mathrm{~kg}$. We therefore retested the alligator dataset by sampling only individuals $>60 \mathrm{~kg}(\sim 2.45 \mathrm{~m}$ long, Chabreck and Joanen 1979:Fig. 2) in the same way as above.

\section{RESULTS}

It is evident from the growth curves that the alligator spends the majority of its life growing, only approaching asymptotic size near the end of its lifespan (Fig. 3A). By contrast, the rhea reaches somatic maturity within the first year, and spends the majority of its life at asymptotic size (Fig. 3B). Predictably, despite the greater size dimorphism exhibited by the alligator and the lesser overlap of its point distribution, the ability to recover a sexually dimorphic signal by randomly sampling along the growth curve is consistently higher in the rhea (Fig. 4A). This reflects the fact that a greater proportion of the sampled points occur within the asymptotic portion of the rhea growth curve, where dimorphism is mostly strongly expressed (i.e., controlling for age makes no practical difference); size dimorphism is obscured when randomly sampling the protracted alligator growth curve because, without controlling for age, younger males resemble older females.

Growth curve shape, the degree of sexual dimorphism, and variance likewise influence the minimum sample size necessary to recover a dimorphic signal. For rheas, a minimum sample of $\mathrm{n} \approx 15$ per sex is necessary to detect dimorphism at $\alpha=0.05$; for alligators, the minimum sample size is much greater at $\mathrm{n} \approx 35$ (Fig. $4 \mathrm{~A}$ ).

Accounting for population structure in the alligator dataset (Fig. 5) favours the sampling of younger, smaller individuals over older, larger ones. This greatly reduces the ability to detect sexual dimorphism, such that even sample sizes of 100 per sex cannot return a near-significant result, reflective of the great size overlap between young males and females (Fig. 4B).

When an artificial size bias against young individuals $<60 \mathrm{~kg}$ is introduced into the alligator dataset (Fig. 4C), it increases the likelihood of recovering a dimorphic signal by up to $\sim 35 \%$. Whereas the unbiased dataset attains significance at $\mathrm{n} \approx 35$ per sex, the biased dataset attains significance at $\mathrm{n} \approx 25$. This enhanced statistical power 
stems from the fact that a greater number of individuals are being sampled near asymptotic size where sexual dimorphism is most strongly expressed.

\section{DISCUSSION}

Given the similarities in growth patterns between dinosaurs and crocodilians with relatively long growth periods (e.g., Myhrvold 2013, Erickson 2014), the alligator dataset is a better proxy for assessing dimorphism in dinosaurs than that of the rhea. Protracted growth in the alligator greatly limits the ability to detect sexual dimorphism in the absence of age control, even when the sexes are known a priori, which is rarely the case for dinosaurs (although there are exceptions: Schweitzer et al. 2005, Lee and Werning 2008). These frustrations echo those voiced previously by Smith and Fisher (2011) when trying to detect dimorphism in indeterminately growing mammoth tusks. Dimorphism is much easier to detect in the fast growing rhea because random sampling preferentially selects among the fully differentiated adults. Some advanced maniraptorans likewise appear to reach adulthood early in life, but growth seems quite variable even among closely related species (Erickson et al. 2007; but see Myhrvold 2013). Among dinosaurs, an avian-style growth curve (where asymptotic size is reached early in life) appears to be the exception rather than the rule.

Predictably, increasing sample size improves the likelihood of signal recovery, yet even at the lower suggested number of 15 specimens per sex that comes from analysis of the rhea data, this value remains unattainable for most dinosaur species known to date (Mallon in press). There are certainly no published datasets that approach the 35 specimens per sex prescribed for relatively slow-growing species. For example, mass mortality sites, including ceratopsian (Ryan et al. 2001), hadrosaurid (Hone et al. 2014, Woodward et al. 2015), and theropod (Colbert 1989, Carpenter 2010) bonebeds, rarely exceed many more than 50 total individuals. Even then, most of the available material tends to be from incomplete, scattered, and taphonomically distorted specimens, rendering much of the data unusable. Some taxa known from large numbers of individuals (e.g. Psittacosaurus, Protoceratops) come from multiple different sites and fossil beds (e.g. You and Dodson 2004). Individuals from different populations may have lived in differing environments and climates, and some individuals would grow at different rates or to different sizes under differing conditions (e.g., Hutton 1987; Madsen and Shine 1993; Cilliers et al. 1995). In addition to potential differences between populations in terms of size and growth rates, degrees of dimorphism can vary between populations of single species, and even in direction (i.e. males may be larger in one population, and females larger in another see examples in Lovich and Gibbons 1992) so caution should be taken when dealing with pooled data. In such instances, it is therefore paramount to control for the possibility of population mixing or chronospecies (Scanella et al. 2014).

The effect of population structure, a reflection of survivorship strategy, warrants some consideration. A Type III strategist such as the alligator maintains a high proportion of short-lived young among its ranks, greatly reducing the probability that random sampling of the population will recover a sexually dimorphic signal. However, 
most of these young succumb to predation early on (Nichols et al. 1976), and stand little chance of becoming fossilised. This scenario would increase the likelihood of detecting dimorphism in the remaining adults. The handful of dinosaurs for which survivorship curves have been reconstructed to date appear to adhere to a sigmoidal B1 type curve (Erickson et al. 2006, 2009, 2010, Steinsaltz and Orzack 2011, Woodward et al. 2015), characterized by an initial period of high mortality (likely due to predation [Hone and Rauhut 2010]), followed by a period of low mortality, culminating in senescent attrition. This, too, would increase the likelihood of sampling mature individuals where dimorphism is most strongly expressed. Taphonomic size bias against small individuals (Brown et al. 2013) would further enhance the effect.

Yet other biological sources of variation would tend to further impede the detection of sexual dimorphism. Differential maturation patterns have been noted in some of the larger sauropods, which may have had unusual population structures and growth patterns, and few, if any, individuals reached somatic maturity (Hone et al. 2016). In such instances, dimorphism may be detectable only if the ages of all individuals are known. Yet some dinosaurs apparently show a high range of variation of size even within single age classes (e.g. Sander and Klein 2005), a condition that dates back to the earliest forms (Griffin and Nesbitt 2016), and one which could further confound tests for dimorphism. This variation has been suggested to be the result of environmental plasticity (e.g. Sander and Klein 2005) or possibly sexual dimorphism (Erickson 2014), but these alternatives remain to be tested. Moreover, even larger juveniles or subadults may lack the characteristic features that permit their correct assignment to a given species, or genus (Sampson et al. 1997, Farke et al. 2013), potentially limiting the pool of data available for detecting dimorphism.

Behavioural or ecological differences between the sexes erect still more barriers to successfully detecting dimorphism in the fossil record. Many extant species may form sex segregated groups or aggregations, or males and females may occupy different environments, or differing mortality for one sex might lead to uneven distribution of the sexes. As a result, large groups of dinosaur specimens, or even multiple specimens collected from different localities, may still be highly biased towards one sex.

Sexual dimorphism varies along a continuum; in some species there is relatively little difference between the sexes (e.g. Iguana, Fitch 1981; Fig 1A) whereas in others (e.g. Tragelaphus, Castelló 2016) there are such dramatic differences that some sexual morphs of extant taxa have even been identified as separate species (Skúlason and Smith 1995). Dimorphic features may become exaggerated with age in some individuals (e.g., the cranium of Elephas, Lister and Blashford-Snell 1999), and apparently distinct morphs may switch from one form to another over time (e.g., bill wear in the oystercatcher, Haematopus ostralegus, Skúlason and Smith 1995).

Dimorphism is therefore likely to be difficult to detect in dinosaurs, even if it was present. Importantly, the argument that we are presently unable to detect dimorphism in dinosaurs is not simply rooted in an absence of evidence. As we show here, the argument is based on positive evidence from modeling of extant taxa. 
Although here we use data on SSD, the same effects and issues would also be true of other aspects of dimorphism such as differences in ornamentation morphology. Critically, a failure to detect dimorphism, even when there is a large sample size, does not immediately mean that it is not present (Mallon in press). For example, the alligator shows some of the highest levels of dimorphism recorded for reptiles. In a survey of sexual size dimorphism, Fitch (1981) reported that the oldest group of males was $150 \%$ of the length of similarly aged females (higher even than the $136 \%$ difference seen in the data used here), and younger adults still differed by $120 \%$. This contrasts sharply with other SSD records in extant reptiles that rarely exceed $135 \%$ (Fitch 1981). In short, detecting dimorphism in the alligator should be easier than in many other species, and thus smaller differences may require considerably larger sample sizes to detect than the 25-35 specimens per sex reported here.

Note that here we make no distinction between sexual dimorphism (be it in body size, or in the presence or size of various ornaments or other physical traits) driven by sexual selection and that driven primarily by ecomorphological divisions (as in, for example, the extinct huia Heteralocha acutirostris, Lambert et al. 2009). However the same issues would hold true. Similarly, these issues of dimorphism might well apply to other narrow separations of morphologically distinct groups such as closely related species, especially where heterochrony is concerned.

Although we do not address the issue specifically here, the problem of cryptic species or those only separated by subtle differences will have the same sampling problem. A morphospecies concept is near universally applied to fossil vertebrates and certainly taxa can be identified from single, and even incomplete, specimens if they demonstrate unique traits or unique combinations of traits. However, species have been identified at least in part on the basis of differences such as being robust or gracile (e.g., Von Huene 1908, Larson 2008, Paul 2008), and our results suggest this will be very hard to demonstrate effectively without large sample sizes. The taxonomic decision to erect or synonymise species (or genera) will take far more than this into account, but clearly caution should be taken when considering subtly different and non-binary characters such as body size. Equally, it is important to correctly identify species to the correct genus and / or species when assessing dimorphism. Two similar, closely related monomorphic species that are sympatric could easily be misinterpreted as a single dimorphic species and the converse may also be true.

\section{CONCLUSIONS}

Chapman et al. (1997:91) concluded that "dinosaurs are an excellent group for the study of sexual dimorphism", but based on currently available data that is not true. Virtually all studies purporting sexual dimorphism in dinosaurs have failed to control for age, which critically limits the ability to detect dimorphism in species with protracted growth, even when the sexes are known a priori. The issue is compounded further by small sample sizes, incomplete specimens, and geographically or time-averaged samples. Very few dinosaur species are currently represented by enough specimens to warrant statistical analysis, but with the ever increasing number 
of finds this is likely to change in the near future. Even so, efforts to absolutely age the specimens using skeletochronology will likewise need to intensify. Although the general low numbers of juvenile dinosaurs might enhance the detection of dimorphism by creating a bias towards older, and therefore more dimorphic, animals, the problems of incomplete animals of unknown age and sex, often from disparate populations, makes this difficult. Our subsampling suggests that, even for strongly dimorphic populations of animals that spend most of their lives below the size asymptote, in excess of 35 individuals per sex might be needed to detect a statistical difference in dimorphism. Failure of such a test does not necessarily indicate that dimorphism is absent; it may instead suggest that individuals of only a single sex have been sampled, that dimorphism is subtle, or that sampling of different ages and growth has resulted in a cryptic signal.

Species that mature at small size and then continue to grow (as in dinosaurs) can show very different size distributions of males and females in populations (see Stamps 1993 for a review and references therein). Indeed, it has been stated that "one cannot interpret spatial, temporal or interspecific variation in sexual size dimorphism in animals with asymptotic growth after maturity without considering the patterns of growth and maturation for the males and females in that group" (Stamps 1993, p. 124). Since we cannot easily identify males and females of dinosaurs let alone determine growth rates of each sex, this would seem to be a potentially intractable problem for identifying dimorphism in dinosaurs.

We hesitate to deem the search for sexual dimorphism in dinosaurs a lost cause, but we are not optimistic in the short term. Dimorphism may be present, and even common, in non-avian dinosaurs (and by extension, in other fossil reptiles, or even animals) but in the vast majority of cases we lack a necessarily large dataset of well-preserved specimens for which it can be tested.

Acknowledgements: We thank Dani Faser for help in R. Ben Borkovic and Rob Knell are thanked for their constructive comments and discussion of an earlier version of this manuscript. Thanks also to two anonymous reviewers for their constructive feedback, and to Phil Mannion and Andrew Smith for their editorial assistance.

\section{DATA ARCHIVING STATEMENT}

Data for this study are available in the Dryad Digital Repository: http://datadryad.org/review?doi=doi:10.5061/dryad.d5r18. File contains R code for modelling Alligator and Rhea growth curves, including population structure and taphonomic bias, and subsampling routines.

\section{REFERENCES}

BirdLife International. 2017. Species factsheet: Rhea americana. Downloaded from http://www.birdlife.org on 15/03/2017. 
BORKOVIC, B. and RUSSELL, A., 2014. Sexual selection according to Darwin: a response to Padian and Horner's interpretation. Comptes Rendus Palevol , 13, 701-707.

BROWN, C. M., EVANS, D. C., CAMPIONE, N. E., O'BRIEN, L. J. and EBERTH, D. A. 2013. Evidence for taphonomic size bias in the Dinosaur Park Formation (Campanian, Alberta), a model Mesozoic terrestrial alluvial-paralic system. Palaeogeography, Palaeoclimatology, Palaeoecology, 372, 108-122.

BRYANT, H. N. and RUSSELL, A.P. 1992. The role of phylogenetic analysis in the inference of unpreserved attributes of extinct taxa. Philosophical Transactions of the Royal Society of London B: Biological Sciences, 337, 405-418.

CARPENTER, K. 2010. Variation in a population of Theropoda (Dinosauria): Allosaurus from the Cleveland-Lloyd Quarry (Upper Jurassic), Utah, USA. Paleontological research, 14, 250-259.

CASTANET, J., ROGERS, K. C., CUBO, J. and JACQUES-BOISARD, J. 2000.

Periosteal bone growth rates in extant ratites (ostriche and emu). Implications for assessing growth in dinosaurs. Comptes Rendus de l'Académie des sciences-Series III-Sciences de la Vie, 323, 543-550.

CASTELlÓ, J. R. 2016. Bovids of the World. Princeton University Press, Princeton. $664 \mathrm{pp}$

CHABREK, R. H. and JOANEN, T. 1979. Growth rates of American alligators in Louisiana. Herpetologica, 51-57.

CHAPMAN, R. E., WEISHAMPEL, D. B., HUNT, G. and RASSKIN-GUTMAN, D. 1997. Sexual dimorphism in dinosaurs. Dinofest international, 83-93.

CILLIERS, S. C., DU PREEZ, J. J., MARTIZ, J. S. and HAYES, J. P. 1995. Growth curves of ostriches (Struthio camelus) from Oudtshoorn in South Africa. Animal Science, 61, 161-164.

COLBERT, E. H. 1989. The Triassic dinosaur Coelophysis. Museum of Northern Arizona Bulletin, 57,1-160.

COOPER, R.G. 2005. Growth in the ostrich (Struthio camelus var. domesticus). Animal Science Journal, 76, 1-4.

COX, R. M., BUTLER, M. A. and JOHN-ALDER, H. B. 2007. The evolution of sexual size dimorphism in reptiles. Sex, size and gender roles: evolutionary studies of sexual size dimorphism, 5, 38-49.

CUNNINGHAM, J. T. 1900. Sexual dimorphism in the animal kingdom: A Theory of the evolution of secondary sexual characters. Adam and Charles Black.

DODSON, P. 1975. Taxonomic implications of relative growth in lambeosaurine hadrosaurs. Systematic Biology, 24, 37-54.

DODSON, P. 1976. Quantitative aspects of relative growth and sexual dimorphism in Protoceratops. Journal of Paleontology, 3, 929-940.

DU PREEZ, J. J., JARVIS, M. J. F., CAPATOS, D. and De KOCK, K. 1992. A note on growth curves for the ostrich (Struthio camelus). Animal Production, 54, $150-152$.

ERICKSON, G. M. 2014. On dinosaur growth. Annual Review of Earth and Planetary Sciences, 42, 675-697. 
-, MAKOVICKY, P. J., CURRIE, P. J., NORELL, M. A., YERBY, S. A. and BROCHU, C. A. 2004. Gigantism and comparative life-history parameters of tyrannosaurid dinosaurs. Nature, 430, 772-775.

-, CURRIE, P. J., INOUYE, B. D., and WINN, A. A. 2006. Tyrannosaur life tables: An example of nonavian dinosaur population biology. Science, 313, 213-217.

—, ROGERS, K. C., VARRICCHIO, D.J., NORELL, M. A. and XU, X. 2007. Growth patterns in brooding dinosaurs reveals the timing of sexual maturity in non-avian dinosaurs and genesis of the avian condition. Biology Letters, $\mathbf{3}$, $558-561$.

—, MAKOVICKY, P. J., INOUYE, B. D., ZHOU, C.-F., and GAO, K.-Q. 2009. A life table for Psittacosaurus lujiatunensis: Initial insights into ornithischian dinosaur population biology. Anatomical Record, 292, 1514-1521.

-, CURRIE, P. J., INOUYE, B. D., WINN, A. A. 2010. A revised life table and survivorship curve for Albertosaurus sarcophagus based on the Dry Island mass death assemblage. Canadian Journal of Earth Sciences, 47, 1269-1275.

EVANS, D. C. 2010. Cranial anatomy and systematics of Hypacrosaurus altispinus, and a comparative analysis of skull growth in lambeosaurine hadrosaurids (Dinosauria: Ornithischia). Zoological Journal of the Linnean Society, 159, 398-434.

FAIRBAIRN, D. J., WOLF, U. BLANCKENHORN, and SZÉKELY, T. 2007. Sex, size and gender roles: evolutionary studies of sexual size dimorphism. Oxford University Press, Oxford, 259 pp.

FARKE, A. A., CHOK, D. J., HERRERO, A., SCOLIERI, B. and WERNING, S. 2013. Ontogeny in the tube-crested dinosaur Parasaurolophus (Hadrosauridae) and heterochrony in hadrosaurids. PeerJ, 1, p.e182.

FITCH, H. S. 1981. Sexual size differences in reptiles. Miscellaneous Publications of the Museum of Natural History University of Kansas, 70, 1-72.

GOODWIN, M. B. and HORNER, J. R. 2004 Cranial histology of pachycephalosaurs (Ornithischia: Marginocephalia) reveals transitory structures inconsistent with headbutting behavior. Paleobiology, 30, 253-267.

GRIFFIN, C. T. and NESBITT, S. J. 2016. Anomalously high variation in postnatal development is ancestral for dinosaurs but lost in birds. Proceedings of the National Academy of Sciences, 113, 14757-14762.

HAMMER, Ø., HARPER, D. A. T. and RYAN, P. D. 2001. PAST-palaeontological statistics, ver. 1.89. Palaeontologia electronica, 4.

HONE, D. W. E.. and MALLON, J. 2017. Data from: Protracted growth impedes the detection of sexual dimorphism in non-avian dinosaurs. Dryad Digital Repository. doi: 10.5061/dryad.d5r18

— and CUTHILL, I. C. 2012. Does mutual sexual selection explain the evolution of head crests in pterosaurs and dinosaurs? Lethaia, 45, 139-156.

- and RAUHUT, O. W. M. 2010. Feeding behaviour and bone utilization by theropod dinosaurs. Lethaia, 43, 232-244.

- and NAISH, D. 2013. The 'species recognition hypothesis' does not explain the presence and evolution of exaggerated structures in non-avialan dinosaurs. 
Journal of Zoology, 290, 172-180.

-, SULLIVAN, C., ZHAO, Q., WANG, K. and XU, X. 2014. Body size distribution in a colossal hadrosaurid death assemblage from the Upper Cretaceous of Zhucheng, Shandong Province, China. 524-531. In EBERTH, D. A. and EVANS, D. C. (eds.) Hadrosaurs. Indiana University Press, Bloomington, 640 pp.

-, FARKE, A. A. and WEDEL, M. J. 2016b. Ontogeny and the fossil record: what if anything is an adult dinosaur? Biology Letters, 12, 20150947.

—, WOOD, D. and KNELL, R. J. 2016. Positive allometry for exaggerated structures in the ceratopsian dinosaur Protoceratops andrewsi supports socio-sexual signaling. Palaeontologia Electronica, 19.1.5A.

HORNER, J. R., DE RICQLÈS, A. and PADIAN, K. 2000. Long bone histology of the hadrosaurid dinosaur Maiasaura peeblesorum: growth dynamics and physiology based on an ontogenetic series of skeletal elements. Journal of Vertebrate Paleontology, 20, 115-129.

HUTTON, J. M. 1987. Growth and feeding ecology of the Nile crocodile Crocodylus niloticus at Ngezi, Zimbabwe. Journal of Animal Ecology, 56, 25-38.

ISLES, T. E. 2009. The socio-sexual behaviour of extant archosaurs: implications for understanding dinosaur behaviour. Historical Biology, 21,139-214.

KING, R. B., STANFORD, K.M., JONES, P. C. and BEKKER, K. 2016. Size Matters: Individual Variation in Ectotherm Growth and Asymptotic Size. PloS one, 11, p.e0146299.

KNELL, R., NAISH, D., TOMPKINS, J. L. and HONE, D. W. E. 2013 Sexual selection in prehistoric animals: detection and implications. Trends in Ecology \& Evolution, 28, 38-47.

LAMBERT, D. M., SHEPHERD, L. D., HUYNEN, L., BEANS-PICÓN, G., WALTER, G. H. and MILLAR, C. D. 2009. The molecular ecology of the extinct New Zealand Huia. PLoS One, 4, p.e8019.

LARSON, P. L. 2008. Variation and sexual dimorphism in Tyrannosaurus rex. 103-128. In P. LARSON and K. CARPENTER, (eds.) Tyrannosaurus rex: the tyrant king. Indiana University Press, Bloomington.

LEE, A. H. and WERNING, S. 2008 Sexual maturity in growing dinosaurs does not fit reptilian growth models. Proc. Natl Acad. Sci. USA 105, 582-587.

LISTER, A. M. and BLASHFORD-SNELL, J. 1999. Exceptional size and form of Asian elephants in western Nepal. Elephant, 2, 33-36

LOVICH, J. E. and GIBBONS, J. W. 1992. A review of techniques for quantifying sexual size dimorphism. Growth Development and Aging, 56, 269-269.

MADSEN, T. and SHINE, R. 1993. Phenotypic plasticity in body sizes and sexual size dimorphism in European grass snakes. Evolution, 47, 321-325.

MAIORINO, L., FARKE, A.A., KOTSAKIS, T., AND PIRAS, P. 2015. Males Resemble Females: Re-Evaluating Sexual Dimorphism in Protoceratops andrewsi (Neoceratopsia, Protoceratopsidae). PLoS ONE, 10:e0126464.

MALLON, J. C. In press. Recognizing sexual dimorphism in the fossil record: Lessons from non-avian dinosaurs. Paleobiology. 
MYHRVOLD, N. P. 2013. Revisiting the estimation of dinosaur growth rates. PLoS One, 8, p.e81917.

NAVARRO, J. L., VIGNOLO, P. E., DEMARÍA, M. R., MACEIRA, N. O. and MARTELLA, M. B. 2005. Growth curves of farmed Greater Rheas (Rhea americana albescens) from central Argentina. Archiv fur Geflugelkunde, 69, 90-93.

NICHOLS, J. D., VIEHMAN, L., CHABRECK, R. H. and FENDERSON, B. 1976. Simulation of a commercially harvested alligator population in Louisiana. Louisiana Agricultural Experiment Station Bulletin, 691, 1-59.

PADIAN, K. and HORNER, J. R. 2011a. The evolution of 'bizarre structures' in dinosaurs: biomechanics, sexual selection, social selection or species recognition? Journal of Zoology, 283, 3-17.

- 2011b. The definition of sexual selection and its implications for dinosaurian biology. Journal of Zoology, 283, 23-27.

- 2014. The species recognition hypothesis explains exaggerated structures in non-avialan dinosaurs better than sexual selection does. Comptus Rendus Palevol, 13, 97-107.

PAUL, G. S. 2008. A revised taxonomy of the iguanodont dinosaur genera and species. Cretaceous Research, 29, 192-216.

R Core Team, 2015. R: A language and environment for statistical computing. $\mathrm{R}$ Foundation for Statistical Computing, Vienna, Austria.

RYAN, M. J., RUSSELL, A. P., EBERTH, D. A. and CURRIE, P. J. 2001. The taphonomy of a Centrosaurus (Ornithischia: Certopsidae) bone bed from the Dinosaur Park Formation (Upper Campanian), Alberta, Canada, with comments on cranial ontogeny. Palaios, 16:482-506.

SAMPSON, S. D., RYAN, M. J. and TANKE, D. H. 1997. Craniofacial ontogeny in centrosaurine dinosaurs (Ornithischia: Ceratopsidae): taxonomic and behavioural implications. Zoological Journal of the Linnean Society, 121, 293-337.

SANDER, P. M. and KLEIN, N. 2005. Developmental plasticity in the life history of a prosauropod dinosaur. Science, 310, 1800-1802.

SCANELlA, J. B., FOWLER, D. W., GOODWIN, M.B. and Horner, J. R. 2014. Evolutionary trends in Triceratops from the Hell Creek Formation, Montana. PNAS, 15,10245-50.

SCHWEITZER, M. H., WITTMEYER, J. L. and HORNER, J. R. 2005. Gender-specific reproductive tissue in ratites and Tyrannosaurus rex. Science, 308, 1456-1460.

SHINE, R. 1989. Ecological causes for the evolution of sexual dimorphism: A review of the evidence. Quarterly Review of Biology, 64, 419-461.

SKÚLASON, S. and SMITH, T. B. 1995. Resource polymorphisms in vertebrates. Trends in Ecology \& Evolution, 10, 366-370.

SMITH, K. M. and FISHER, D. C. 2011. Sexual dimorphism of structures showing indeterminate growth: tusks of American mastodons (Mammut americanum). Paleobiology, 37, 175-194. 
STAMPS, J. A. 1993. Sexual size dimorphism in species with asymptotic growth after maturity. Biological Journal of the Linnaean Society, 50, 123-145.

STEINSALTZ, D. and ORZACK, S. H. 2011. Statistical methods for paleodemography on fossil assemblages having small numbers of specimens: an investigation of dinosaur survival rates. Paleobiology, 37, 113-125.

SZÉKELY, T., LISLEVAND, T. and FIGUEROLA, J. 2007. Sexual size dimorphism in birds. 27-37. In FAIRBAIRN, D. J., WOLF, U. BLANCKENHORN, and SZÉKELY, T. (eds) 2007. Sex, size and gender roles: evolutionary studies of sexual size dimorphism. Oxford University Press, Oxford.

VON HUENE, F. 1908 Die Dinosaurier der europäischen Triasformation mit Berücksichtigung der aussereuropäischen Vorkommnisse. Geologische und Paläontologische Abhandlungen, 1, 1-419.

WILKINSON, P. M. and RHODES, W. E. 1997. Growth rates of American alligators in coastal South Carolina. Journal of Wildlife Management, 61, 397-402.

WITMER, L. M. 1995. The extant phylogenetic bracket and the importance of reconstructing soft tissues in fossils. 19-33. In THOMASON, J. J. (ed.)

Functional morphology in vertebrate paleontology. Cambridge University Press.

WOODWARD, H. N., FREEDMAN FOWLER, E. A., FARLOW, J.O. and HORNER, J. R. 2015 Maiasaura, a model organism for extinct vertebrate population biology: a large sample statistical assessment of growth dynamics and survivorship. Paleobiology, 41, 503-527.

YOU, H. and DODSON, P. 2004. Basal ceratopsia. 478-493. In WEISHAMPEL, D. B., DODSON, P. and OSMOLSKA, H. The Dinosauria ( $2^{\text {nd }}$ Edition) University of California Press, Berkeley, 861pp.

Figure captions: 

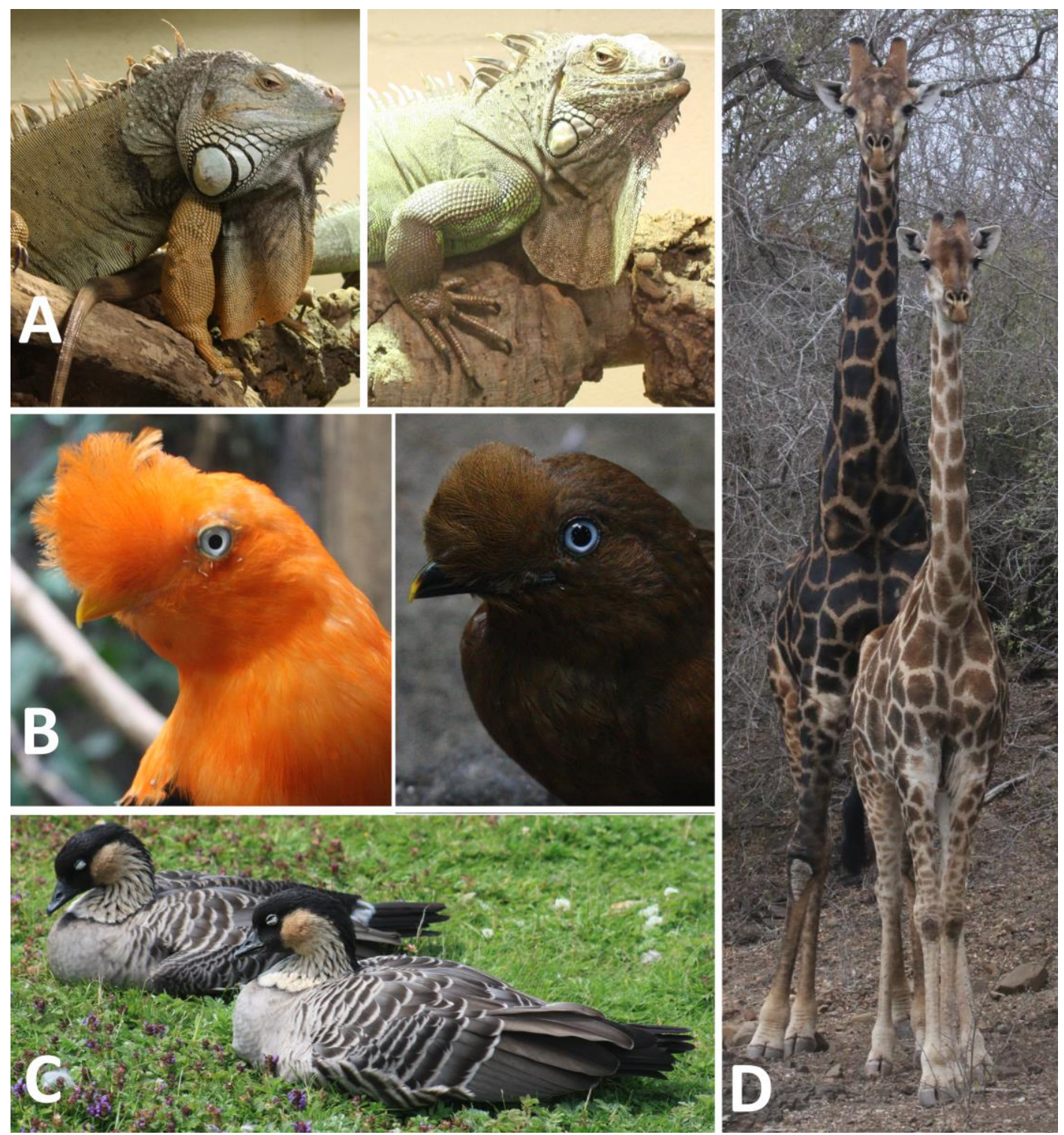

Fig 1. Montage of varying degrees of dimorphism for extant animals. Montage of varying degrees of dimorphism for extant animals. A Male (L) and female (R) Green Iguana (Iguana iguana), with differing scales, dewlaps and body sizes, B male (L) and female (R) Andean Cock of the Rock (Rupicola peruvianus) with differing colour and an erectile feather crest in the male $\mathrm{C}$ Hawaiian goose (Branta sandvicensis) showing no dimorphism between the male and female, and D male (rear) and female (front) giraffe (Giraffa camelopardalis) showing different sizes and the larger bony head of the male. 


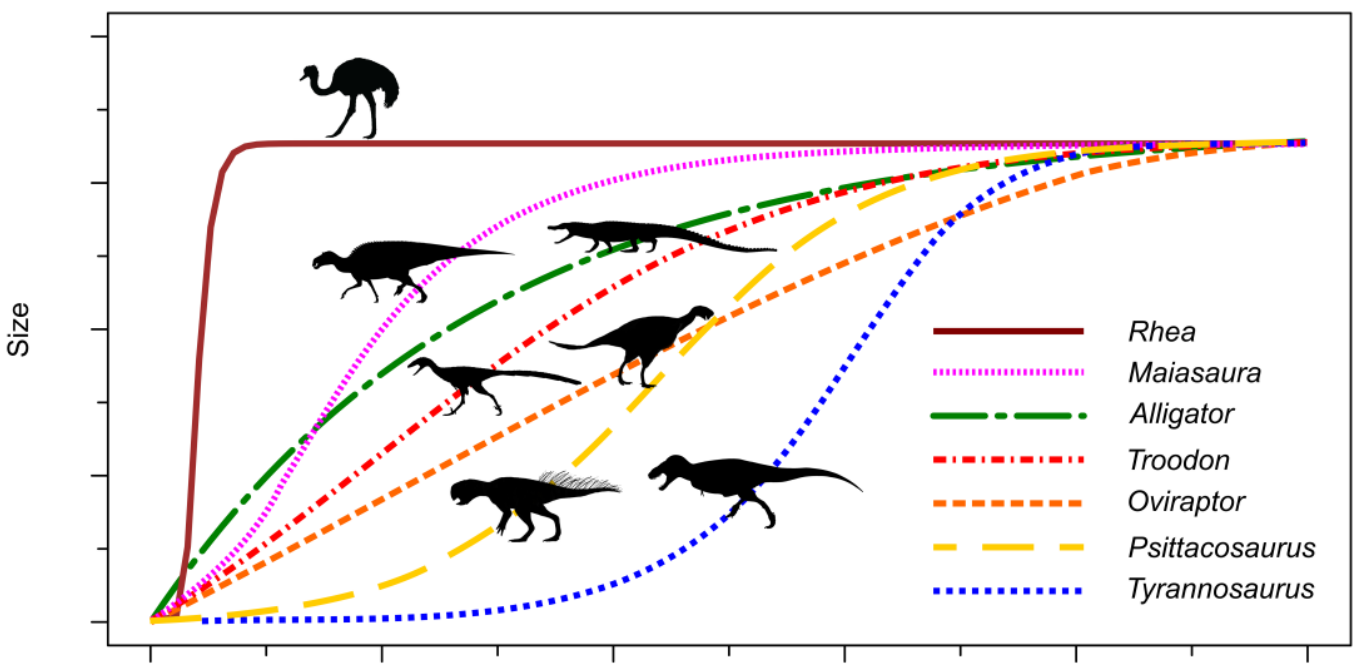

Lifespan

Fig 2. Growth curves of Rhea, Alligator, and various dinosaurs (Maiasaura, Oviraptor, Psittacosaurus, Troodon, Tyrannosaurus), scaled to unit lifespan (data from Wilkinson and Rhodes 1997; Erickson et al. 2004, 2007, 2009; Navarro et al. 2005; Woodward et al. 2015). Image credits (via http://phylopic.org): P. Buchholz, Psittacosaurus; T. M. Keesey, Rhea; S. Hartman, Alligator, Maiasaura, Troodon, Tyrannosaurus; M. Martyniuk, Oviraptor. 


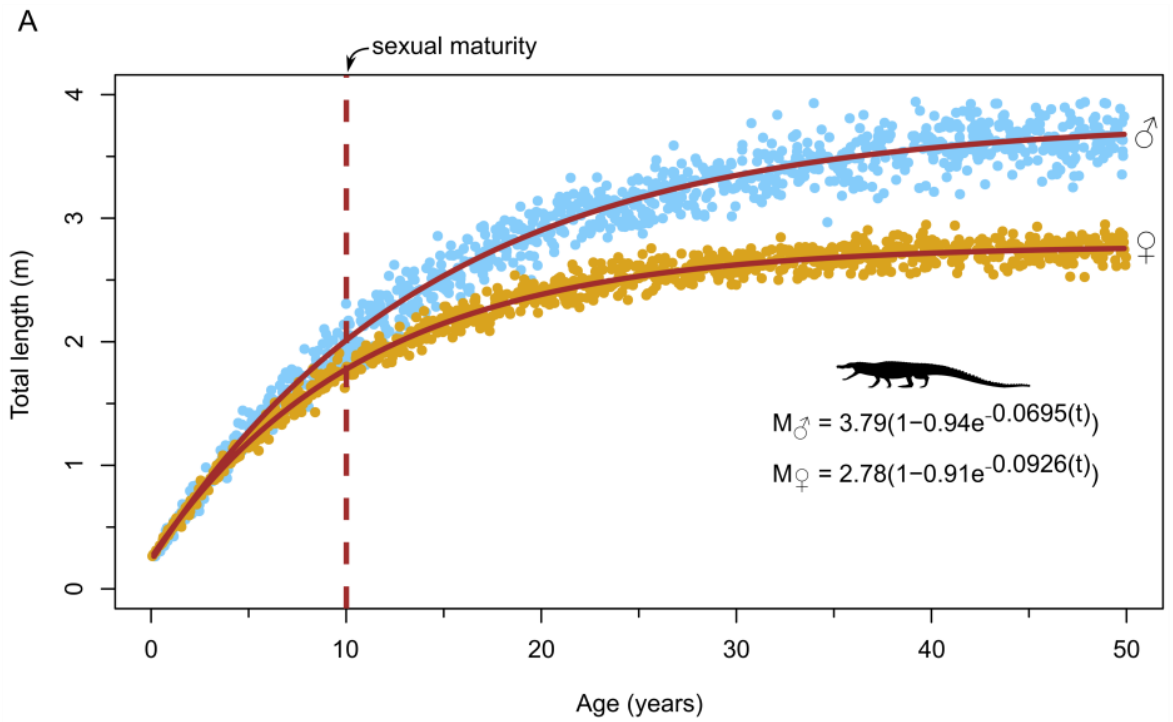

B

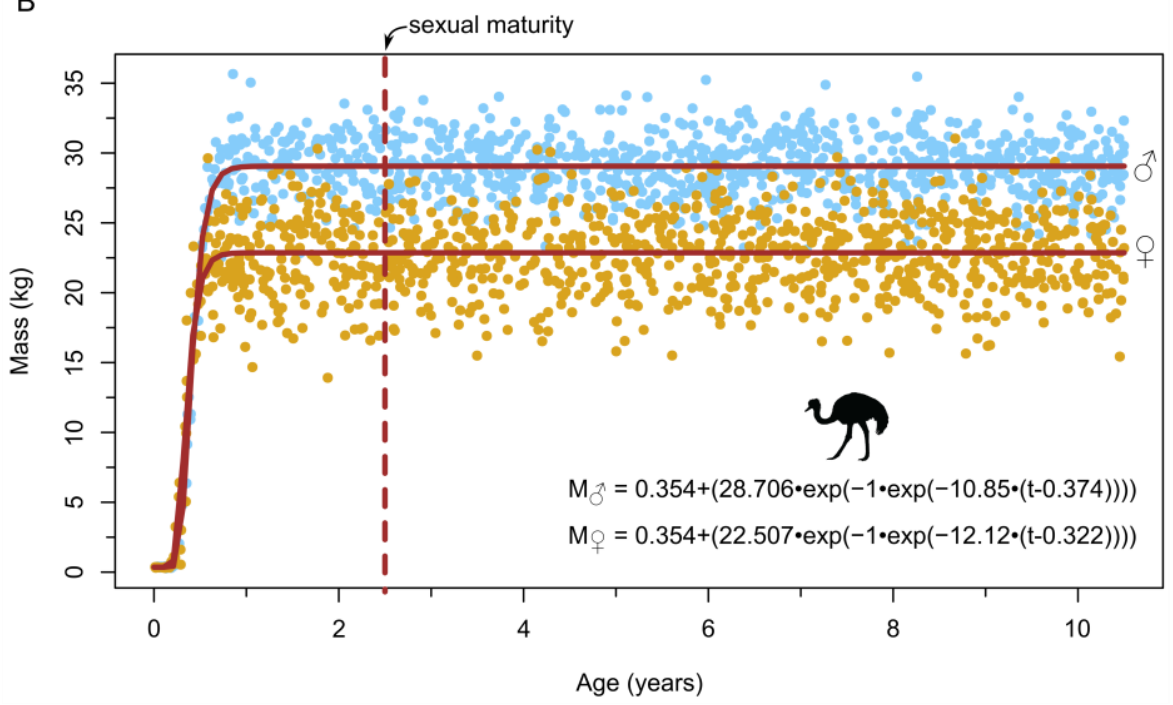

Figure 3. Growth curves for Alligator mississippiensis (A) and Rhea americana albescens $(\mathrm{B})$. 

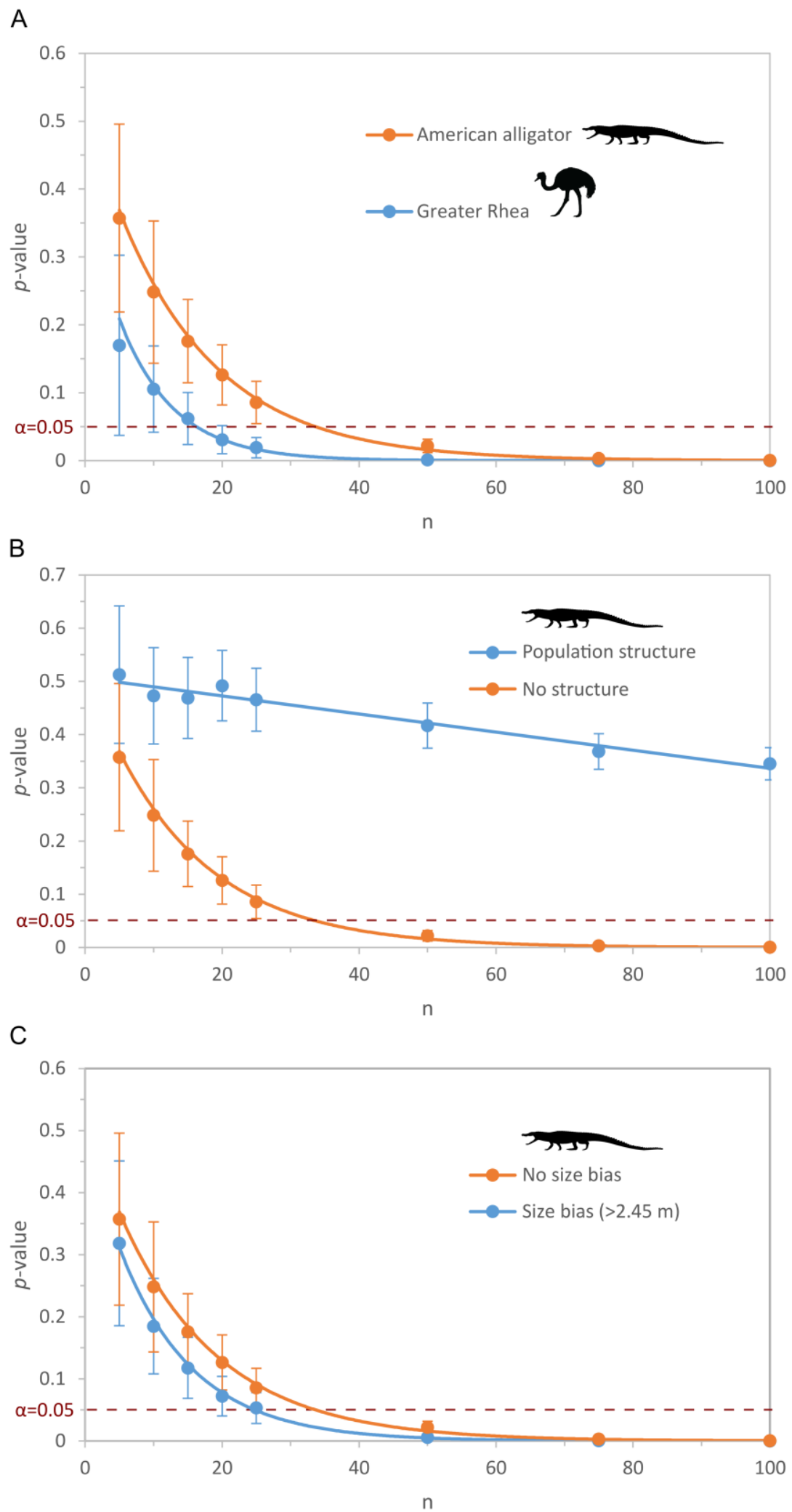

Figure 4. $t$-test results comparing bootstrapped male and female samples. (A) Alligator mississippiensis and Rhea americana albescens; (B) A. mississippiensis results with and without population structure; (C) A. mississippiensis results with and without body size bias. 


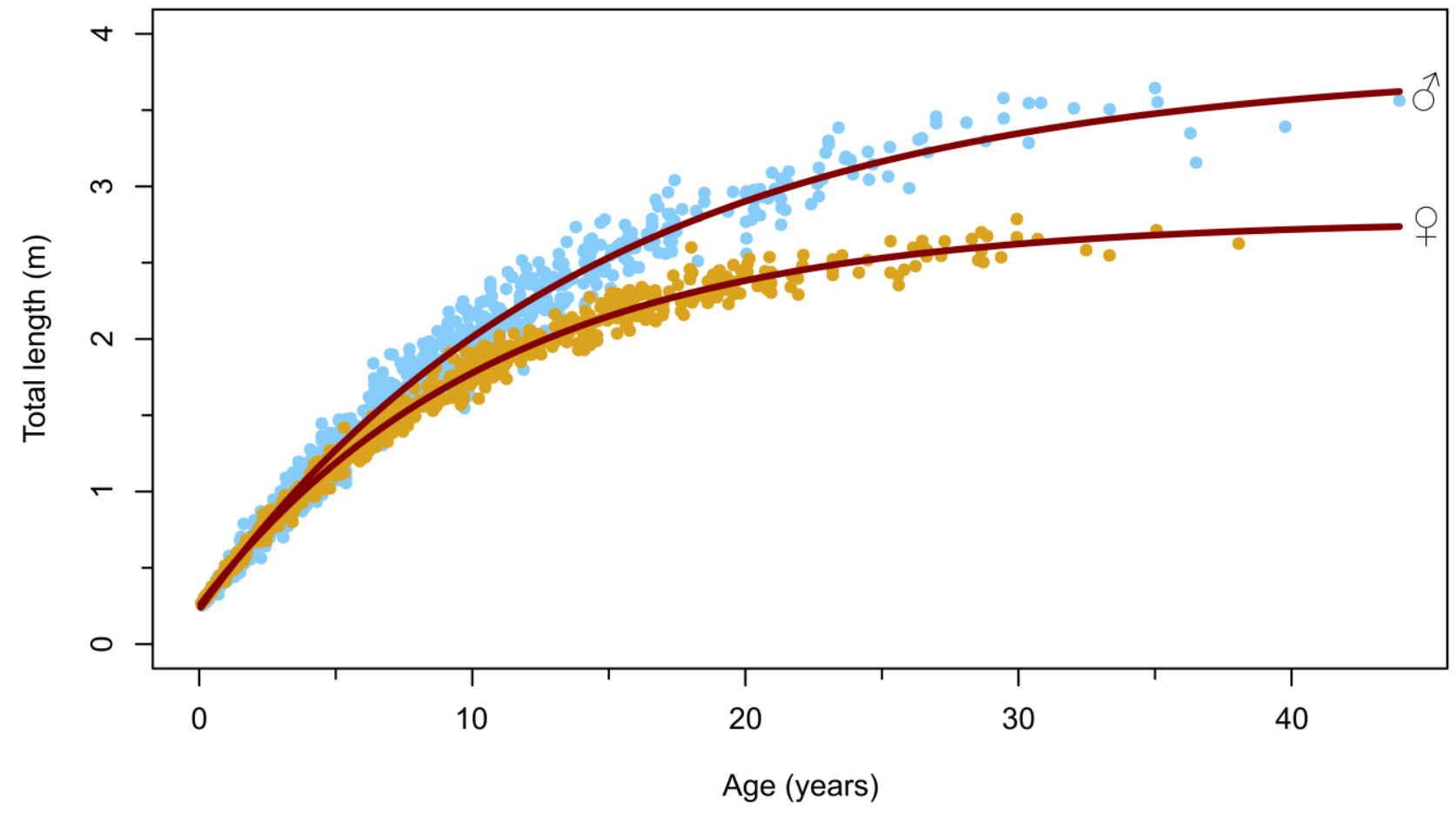

Figure 5. Alligator mississippiensis growth curves incorporating population structure data. There are fewer old adults available for sampling, which reduces the likelihood of detecting sexual dimorphism. 